\title{
Chapter Eight
}

\section{What if the Rich Child has Poor Parents? The relationship from a Flemish perspective}

\author{
Michel Vandenbroeck, Nadine De Stercke and Hildegard Gobeyn
}

In this chapter, we wish to critically analyse the relationship between early childhood education (ECE) and compulsory school education (CSE) with a particular focus on equity in a context of diversity. As the hierarchical relationship between ECE and CSE is dominant in most affluent countries, we will take up the point made by Peter Moss in his introductory essay, that the dominant discourse of readying children to enter school is highly contestable. The readiness paradigm has historically been, and increasingly continues to be, underpinned by a concern about equity and social justice. However, there is good reason to doubt that it keeps its promises. Rather, it seems to be that the readiness paradigm may very well result in increased inequality, excluding precisely those it wishes to include.

Our critical analysis is based on international literature, but deeply embedded in the concrete context of Flanders (the Flemish speaking part of Belgium) for several reasons. It is the region where we live and work. It is also a region with universal access to early childhood education for children from $2 \frac{1}{2}$ years onwards. Full day kleuterschool ${ }^{1}$ is not only universally accessible, it is also free of charge for the parents and teachers are trained to a Bachelor level (ISCED 5). In short, the Flemish kleuterschool meets most international standards (Unicef Innocenti Research Centre, 2008), albeit with rather large groups of 20 to 24 children for one teacher. Yet, results from the PISA studies show that the Flemish education system is among the most unequal in the European Union: in no other European country are the school results of young people so dependent on their families' background (OECD, 2007). This makes Flanders a challenging case to examine the relationship in which ECE is considered to be preparing children for school and, therefore, contributing to "levelling the playing field' by creating equal opportunities.

\footnotetext{
${ }^{1}$ Kleuterschool means 'school for toddlers'. Initially for children from 3 to 6 years of age, since the late 1970 s children from $2 \frac{1}{2}$ years are admitted. Due to the shortage of child care for younger children and the fact that kleuterschool is free for parents (in contrast to child care), growing numbers of children from $2 \frac{1}{2}$ years are enrolled in kleuterschool. Kleuterschool is part of the education system. Together with lagere school (primary school) it forms the basisschool (basic education), although compulsory school starts at 6 .
} 
In his introductory essay, Peter Moss rightly argues that the ethical and political choice about the possible relationships between ECE and CSE is inextricably linked with the image of the child we construct. In our analysis, we will particularly focus on how constructions of the child are intertwined with constructions of the parent, as well as with constructions of the relationship between the family and the (welfare) state, hence the provocative question in the title of this chapter: what if the Rich Child has Poor Parents? We believe that this is an important elaboration, as constructions of childhood cannot be considered without examining constructions of parenthood and of citizenship (Vandenbroeck and Bouverne-De Bie, 2006). Moreover, a recent study of curricula for the initial education of early childhood educators' in 15 European countries (Urban, Vandenbroeck, Lazzari, Peeters and Van Laere, 2011) showed that parents are virtually absent (with some notable exceptions such as the French éducateur jeunes enfants). More attention needs to be given to the relationships between parents and educational services if one wishes to explore the second relationship sketched by Peter Moss, based on the Starting Strong reports: a relationship of equal partnership.

By focusing on parents' points of view, we also wish to further explore the ethical and political possibilities in ECE, with particular attention for the values of democracy. This implies that we not only wish to look at which knowledge is important (as Vecchi (2010) advocates), but also at what this knowledge is for, what education in general is for and, especially, who is enabled to participate in this discussion. But acknowledging the plea made by Peter Moss to take a historical stance, we will first give a short overview of ECE and CSE traditions in Flanders.

\section{A concise hindsight}

In most European countries compulsory schooling was introduced alongside child protection laws and child care, during the first industrial revolution - for Belgium, in May 1914. Space precludes elaborating in detail the rationale for this evolution, but as we have explained elsewhere (Vandenbroeck, 2003, 2006), kinderopvang (child care) for the youngest had several missions. Obviously, it enabled women to go to work, providing a cheap labour force. These working class women were not only poor, but also accused of poor parenting. Child mortality in this era was high, and was not attributed to the harsh living conditions (low wages, poor housing, lack of sanitation) but rather to the incompetence and the neglect of working class mothers. It was the mission of the early crèches to take over the maternal tasks, where mothers were thought to be deficient, as well as to educate and civilise these mothers or, as Donzelot (1977) puts it, as a way of policing the family. 
The first child protection legislation and the prohibition of child labour, at the same time as the emergence of kinderopvang for the youngest children, removed the actual economic role of children in the family and in society, contributing to the construction of the child as fragile and as an investment in the future. As a consequence, parents (i.e. mothers) were constructed as the guardians of these investments and the family - based on the bourgeois family model - was expected to be the cornerstone of the desired society. Failure to conform with the dominant ideal of what constituted maternal attitudes was not only considered as an offence towards the child, but also towards the society (Foucault, 1975). The new child protection laws allowed for far reaching interventions in the family when children (and society) were considered to be 'in danger' and gave the State the right to substitute the 'bad father' (Peters and Walgrave, 1978).

Kleuterschool followed a different path. Rapid growth of bewaarscholen (care schools) occurred between the 1820 s and 1850s. By the late 1850 s, they were not just seen as 'caring places' for the young children of workers, but also as providing education for their middle class counterparts, complementing rather than replacing the education provided by mothers, and even more so as the bewaarscholen turned into kindertuinen (kindergarten), under the influence of Froebel-inspired liberal (and to a lesser extent Catholic) initiatives (Depaepe and Simon, 2005). Due to the influence of feminist figures from the bourgeoisie, such as Gatti de Gamond (1839-1905), by the late $19^{\text {th }}$ century professional education was provided for the (female) teachers, who, unlike crèche workers, were not recruited from among the poor. The kindertuinen, today's kleuterschool, was not associated with a deficient construction of parenting and, as a consequence, spread rapidly, first in the cities, later in more rural areas.

Belgium witnessed a fierce political struggle between Catholics and Liberals about 'the soul of the child'. While the Liberals advocated State education, the Catholics did not accept interference by the State in what they framed as private matters. As a result of this on-going struggle it was decided that there would be no compulsory school (schoolplicht), but compulsory learning (leerplicht), meaning that parents need not enrol their children in primary schools if they could show that they were teaching their children according to the minimum curriculum standards. A second result of the struggle for the soul of the child was that in many municipalities across the country both State and private (but publicly funded) Catholic schools mushroomed, including kleuterschool.

Compulsory learning was intended to make the most of the investment in the (economic) future of the child and promised social mobility (emancipation). But it also served to keep the 
children of the working class off the streets and to civilize them in the new industrial era. As explained above, conservative circles (i.e. the Catholic Party) opposed interventions by the State in 'the freedom of the father', while progressive, liberal sections of society strove for it, pleading for the emancipatory potential of the school, as well as it being an institution for children learning their place in society. The compromise that emerged from this so-called 'school war' was that the state could only intervene when the pater familias was considered to neglect his duties.

In short, both kinderopvang for the youngest and kleuterschool and lagere school (primary education) for older children were newly emerging institutions that can be considered as both emancipative and as a bourgeois attempt to civilise the poor. It should be noted that this occurred in a liberal welfare regime, with a minimal role for the State. The State was expected only to intervene when parents were considered deficient: the so-called État Gendarme (Donzelot, 1977), rather than as a way of redistributing resources and optimizing the (educational and other) opportunities for all. Changes to extend the period of compulsory learning have since then always gone hand in hand with changes in the labour market (i.e. rising unemployment for early school leavers).

We now turn to the late 1960s and early 1970s, important for the present-day discussion about the role of ECE, framing ECE as preparing for CSE in new ways. It was a period of concern about the underachievement of working class (black) children in schools in the United States, following the Sputnik shock: the shock that the Soviet empire could take a technological lead, amidst the Cold War. Large investments were made in compensatory programmes, focusing primarily on compulsory school age. In the early 1970 s, scientists were critical and disappointed when confronted with the lack of persisting effects from these expensive compensatory programmes (e.g. Bronfenbrenner, 1974; Thirion, 1973). As a result of this disappointment, a general consensus rose among scholars that primary school was too late to begin education and investments should be made at an earlier age to prevent children from starting compulsory school with a disadvantage, thus saving the (poor) child as well as the nation through the child (Vandenbroeck, 2003).

The framing of the early years as an optimal period for prevention has been reinforced in new ways since the 1990 s and even more so in the $21^{\text {st }}$ century. Through the OECD's PISA studies (see Chapters One and Two), it is well documented that children from poor families do less well at school. Recently, research has shown that the brain develops most in the early years (for a concise overview see, for instance, Unicef Innocenti Research Centre, 2008) and combining these two mainstream findings, it is now widely accepted that the early 
years present the best return on educational investment (Heckman, 2006). This has led to a consistent plea for access to pre-school provision and enrolment rates are now an important indicator of a nation's well-being (European Commission, 2010, 2011). Based on correlational studies, the OECD (2011) claims that attendance at ECE is significantly related to better school outcomes in adolescence.

It is no coincidence that this prevention or social investment paradigm is dominant in neoliberal welfare states, both in the affluent world and beyond. As Christian Morabito shows in his on-going PhD research, contemporary philosophers - such as Roemer (1998), Rawls (1971) and Sen (2009) - have laid a foundation for a shift in thinking about equality. They advocate taking personal choice, individual effort and merit into account. As a result, they propose the concept of equality of opportunities, rather than equality of outcomes, be it for somewhat different reasons. Political scientists (e.g. Giddens, 2005) have interpreted this concept further, and it has now been 'translated' by politicians who refer to equal opportunities, rather than equalising outcomes, as a compromise position on equality that is supposed to be beyond the traditional left/right divide. In this new discourse, inequality of outcome is not only tolerable in meritocratic societies, it is also supposed to be a necessary condition for economic development; individual effort and merit need should be taken into account when conceptualising equality. Both contemporary philosophers and policy makers explicitly point to education in general and ECE in particular as a means of equalising opportunities in ways that are supposed to be beyond political debate. This argument has also deeply influenced international organisations, including the World Bank, UNICEF and UNESCO (Morabito, 2011).

What is consistent in this history is that ECE has continuously been framed in a prevention paradigm. This implies that the meaning and value of early childhood education does not reside primarily in early childhood itself, but later in life: ECE is only a transitional period for the real education that occurs in CSE. In the same way, the meaning and value of CSE does not reside in that period of education itself, but rather in the economic return it brings as a consequence of finding a place in a competitive labour market.

What is equally consistent is that education is framed as a means to solve social problems (Vandenbroeck, Coussée and Bradt, 2010). Immorality and child mortality in the $19^{\text {th }}$ century, unemployment and intergenerational poverty today are considered as important problems, but are not treated as social problems - rather as educational ones. In so doing, they also become individual problems of children and their families. The solution is, therefore, not to 
look again at the distribution of resources and the growing gap between rich and poor, but at education, stressing individual responsibility for the management of one's own life chances.

Paulo Freire said that '[t]his view mistakenly presupposes that themes exist, in their original, objective purity, outside me - as if themes were things' (Freire, 1970, p.97). He is arguing that a 'problem' - or 'theme' - does not exist as such; it is always socially constructed. Consequently, it can always be de- and re-constructed. Freire argues that there is no such thing as an educational problem per se. Such problems are, according to him, nothing more (and nothing less) than specific forms of social problems. One of the main objectives of his pedagogy and of the 'cultural circles' he installed was to form collective spaces of reflection in order to reconstruct what is considered to be the problem or the 'theme'.

Another continuity is that science is viewed as informing policymakers, practitioners and parents about the truth concerning children and what needs to be done, be it medical science and eugenics in $19^{\text {th }}$ century, developmental psychology in $20^{\text {th }}$ century or brain science and economics in the $21^{\text {st }}$ century. We will now develop this last theme a bit further.

\section{The democratic deficit of education}

ECE has been constructed as a preparatory phase for CSE and also as early prevention. The prevention paradigm is consistent with the concept of the social investment state: a welfare state that does not compensate for failures of the market, but invests to ensure future integration in this highly competitive market (e.g. Featherstone, 2006). Consequently, social welfare became a matter of 'no rights without duties'. Investments in welfare today are also considered as a prevention of later risks, of which the risk of being dependent on the social welfare system (e.g. in the case of unemployment) is one of the more important.

The prevention paradigm and the framing of education as a means to solve potential social problems entails risks being calculated and calls upon science to inform policy makers and practitioners about what works. It is therefore quite understandable that in the neo-liberal social investment state evidence-based policy and practice is foregrounded, to ensure the effectiveness and efficiency of interventions. Researchers are expected to answer the question 'what works?' As Biesta (2007, p.5) explains, this question to researchers entails an important democratic deficit:

Evidence-based education seems to favour a technocratic model in which it is assumed that the only relevant research questions are questions about effectiveness [...] forgetting that what counts as "effective" crucially depends on judgments about 
what is desirable. On the practice side, evidence-based education seems to limit severely the opportunities for educational practitioners to make such judgments in a way that is sensitive to and relevant for their own contextualized settings.

Evidence-based education presupposes that what the educator does is an activity with a specific purpose and that there is a causal relationship to establish between purpose and action. Effectiveness is supposed to be the certain relationship between the intervention and its results. Efficiency is then about the costs of this relationship. Consequently, effectiveness and efficiency do not include a judgment about what needs to be achieved, the only relevant question being how to achieve the predetermined outcomes and the investment necessary to do so.

Yet, education is a highly complex matter in which many variables interfere: context for example, but also how children and parents accept (or refuse) the intentions of the educator, making clear and consistent causal relationships between intervention and effect highly improbable. But, more important, there is the democratic question about who is entitled to establish the educational goals. What is desirable and who says so? The fundamental problem with the prevention paradigm in general and with evidence-based practice in particular is that the goals (the desired outcomes) are defined by the researchers and, therefore, not negotiated with individual families or practitioners, as the goals need to be similar for the entire cohort. These goals are then represented as natural, self-evident and 'objective'. This is what Biesta (2007) labels as the democratic deficit of evidence-based practice. For democratic practice means that parents and children are involved in decisions that concern them (Moss, 2007).

Education is first and foremost an ethical and political act, as it always is (and always will be) related to our vision of the world we would wish our children to live in. Education is after all about 'ways of imagining a possible future' (Biesta, 2007, p.21). Therefore it is ultimately about how we would wish people to be and how we would wish them to relate to society. No doubt we could easily agree on some general horizons including a worldview based on equality, freedom and solidarity. Yet it is highly improbable that we would still agree when it comes to putting this possible future into practice. While some would put individual freedom first and attach much importance to rewarding effort and merit, others may value solidarity and equality more and advocate more strongly for redistributive systems. While some educators stress autonomy, free choice and self-expression as the highest values, others may wish to limit autonomy to favour inter-dependency and belonging (Tobin, Hsueh and Karasawa, 2009). As Sen (2009) explained through the story of the children and the flute, 
there is no such thing as one rational truth about what is 'just'. It is precisely such disagreements and debates about and between diverging viewpoints that are at the heart of what democracy is about (Mouffe, 2005).

\section{The case of Flanders}

The unquestioned assumption that early access to education will benefit performance in CSE and that this may help reduce poverty in the future is seriously challenged by the Flemish case. Flanders has a split system in which child care services for 0 to 3 year olds are part of the welfare system, while kleuterschool ( $2 \frac{1}{2}$ to 6 years) is integrated in the education system, as is CSE. Enrolment in Flemish kleuterschool is among the highest in the world; 97 per cent of children between 3 and 6 years are enrolled and in the last year of kleuterschool, only 0.3 per cent of children are not enrolled (Gobeyn and De Stercke, 2010). Children also go to kleuterschool at an earlier age ( $21 / 2$ years) and for longer hours (about 30 hours per week) than in most countries. In addition, enrolment in kinderopvang (child care) for children from 0 to 3 years is relatively high (around 40 per cent) and has grown substantially over the last two decades (Kind en Gezin, 2010). Yet, school results for Flemish children are, according to the PISA study, influenced more by the socio-economic background of their family than in any other European country and child poverty has doubled in the last decade (Cantillon, 2010).

High enrolment does not necessarily mean that children attend kleuterschool regularly. Figures on attendance (meaning actual presence in the school, rather than administrative enrolment) are scarce, but it is estimated that absence is highest among those groups that are 'at risk' of school failure later on: children from poor families, among which ethnic minorities are over-represented (Vandenbroucke, 2007). Consequently, ethnic minority families are encouraged to send their child more often, more frequently and at an earlier age to kleuterschool, in order to prevent later school failure.

For a few years now, all parents from ethnic minorities and parents living in poverty have received a home visit when their child is between 30 and 36 months to convince them of the benefits of attending kleuterschool. Since September 2009, a new measure has been introduced by the Flemish government. A child cannot enrol in the first year of compulsory school (at age 6), unless she has attended kleuterschool for at least 220 half days (Smet, 2009). If she has not, she will need to do a language test and, failing that, will have to attend kleuterschool, regardless of having reached the primary school age. Obviously, children whose home language is not Flemish will have less chance of passing the test. This new measure implies not only that kleuterschool is formally expected to prepare children for CSE, 
but also that CSE is no longer expected to be able to deal with the diversity of home languages. It also implies that enrolling in the first year of CSE is not an unconditional right anymore, but dependent on earlier attendance at pre-school; a de facto lowering of compulsory school age has been introduced, a measure that is likely to affect ethnic minority children in particular. Finally, parental allowances that are meant to enable the poorest parents to cope with minor school expenses can be withdrawn if their child is too often absent from kleuterschool (Smet, 2009).

We can consider these measures as a way of managing illegalisms, which according to Deleuze (1985) are not 'illegal' acts according to the law, but rather the multitude of things that are either prohibited or labelled as undesirable. According to Deleuze (1985), some illegalisms are permitted, made possible or invented as a privilege of the dominating classes; examples are various tax reductions that favour the already privileged. Some illegalisms are tolerated, as compensation for the dominated classes, such as carnivalesque manifestations in the Bakhtinian sense (Bakhtin, 1984), not only at Carnival time, but also at various public demonstrations. Finally, some illegalisms are prohibited, isolated and made objects of intervention as well as domination. An example in this case is absence from kleuterschool, which cannot be considered against the law as kleuterschool is not compulsory, but still is the object of interventions

From an international perspective, the case of Flanders shows what may be the ultimate consequences of policies and practices that frame ECE as a preparation of CSE in a context of universal accessibility - extending compulsory attendance, de jure or de facto, to ECE. The consequence in Flanders is policing families to attend the service that 'we' have so generously developed for 'them', without 'them' being able to participate in the debate about what kind of education is to be provided, having no say in what they would wish for their children. It is indeed remarkable that the concern about equality has not led to discussions with parents about their expectations of education in general and ECE in particular. As a result, official concern about social inclusion, combined with the concept of a hierarchical relationship between ECE and CSE, has led to practices of coercion and exclusion.

In the following sections we give a concise account of two modest attempts to involve parents in discussions about how they are constructed as parents and how education is constructed. The first example is about ECE, the second about CSE. We end by discussing how these experiences might inspire us to reconceptualise the relationship between ECE and CSE. 


\section{Listening to parents whose children are absent from ECE}

The second and third authors conducted a small scale, exploratory and qualitative study about these issues for their Masters in Social Work thesis, supervised by the first author (Gobeyn and De Stercke, 2010). In this context, they interviewed 11 parents whose children were enrolled in kleuterschool, but were not or rarely attending: three Belgian mothers, one Roma father and one Roma mother, three mothers from Central Europe, two North African mothers and one Central African mother. One purpose of the interviews was to explore parents' perspectives about the meaning of ECE and its relationship with CSE, as well as why their children did not attend ECE, despite the dominant discourse. A first observation is that most of these parents were reluctant to speak to the researchers and often refused to have the interviews tape-recorded; they had assimilated the dominant discourse about being deviant and guilty of bad parenting, which Freire (1970) would label as the culture of silence'. A thematic phenomenological analysis of the parents' narratives leads to three recurrent, interrelated themes.

\section{School readiness}

One of the most cited reasons why parents do not let their children go to kleuterschool is that they feel their child is not 'ready' to be in the large groups in these schools. This is expressed in different ways. A major concern of several parents was that their child was not fully pottytrained and that, in their view, the teacher cannot be bothered with potty training, considering the large groups of children she has to take care of. This is consistent with the view expressed by a Flemish Minister of Education that the kleuterschool teacher must be able to fulfil educational tasks and that changing nappies may hinder this work. Potty training is, according to the Minister, primarily the responsibility of parents (Vandenbroucke, 2008) - and parents entirely agree.

This points, however, at an important aspect of the preschool education system, which was also highlighted in the recent $\mathrm{CoRe}$ study $^{2}$ on competence requirements for the early years workforce in Europe (Urban et al., 2011). In many countries education is considered in a narrow sense, so that caring tasks (such as washing, toileting, meals) are not considered educative. Such tasks are left to unqualified assistants, while qualified teachers concentrate on the 'real' education, leading to a 'split' system (between education and care) even occurring where child care and early education are fully integrated into one system.

\footnotetext{
2 CoRe stands for Competence Requirements in Early Childhood Education and Care, a study commissioned by the European Commission Directorate General for Education and Culture. The study was jointly conducted in 2010-2011 by the University of East London and Ghent University and comprised a literature study, a survey in $15 \mathrm{EU}$ countries and 7 in-depth case studies. The data we refer to in this section are drawn from the survey.
} 
Another example in this vein, mentioned by parents during interviews, was that their child still needs to sleep after lunch and this was not possible in the kleuterschool. As a Belgian mother said: 'School readiness, I don't know really. I think the child will show the moment when he is... He will show if he is ready to go to school'. We see here how this mother has internalised the concept of school readiness as a quality of the child and thus asks how this child needs to be for the school, rather than how one would like the school to be for this child.

\section{Confidence and transitions}

A second recurring theme, also related with the separation of care and education, is transition and trust. Some examples from the interviews:

When I see him in the school...I think he is so young (Belgian mother)

I think I need to protect him. I have always been a protective mother... If I had the money, I would hire a private teacher and make my own library. There is a lot of aggression out there (Algerian mother).

I cannot comfort him when he is in school and has pain or sorrows (Congolese mother).

When they understand the language, they will know when someone is gossiping. The children feel insecure; they do not know when other children are talking badly about them. They don't know what will happen to them (Kosovan mother).

The dominant discourse is that parents find it hard to let their children go and that they need to trust the kleuterschool. However, as we have learned from child care services, confidence is a reciprocal matter that is slowly built during a long transition period, in which parents are not just told how to behave and how to be, but are intensely listened to and 'taken care of' (Vandenbroeck, Roets and Snoeck, 2009). The parents that were interviewed can hardly be confident, since their concern is about care and care is all too often considered as separate from education. In addition, many parents are discouraged from physically being in the school. They are expected either to leave their child at the gate, or to leave the classroom when the 'real' education starts. Moreover, they receive negative feedback from their child, seeing her crying when they leave her in school, or coming home with what they call 'dirty words' and finding no possibility in the kleuterschool to express these worries. The careful (full of care) transition is important for all parents, and probably even more so for 
unemployed parents, since they are less likely to have had previous experience with using child care services.

\section{Poverty}

A third important theme for some of the parents who were interviewed is poverty. This implies many things such as not having the money to buy the necessary bus ticket, not having decent clothes or shoes (and consequently fear that the child will be bullied or not accepted), or even not having a table for doing homework and thus fearing that their child will be criticised by the teacher. And of course poverty also goes together with bad health and frequent illness.

Kleuterschool in Flanders is predominantly child-centred, based on experiential learning and attaches a lot of importance to the 'emergent curriculum' (OECD, 2006), meaning that the life experiences of children are taken as a starting point for building the curriculum. In practice this means that the teacher will attach much importance to circle times, in which she will ask children to express their experiences and develop activities on the basis of this selfexpression. In the interviews, parents show that they understand this very well and they comment that the other children will talk about their outings and holidays and the like. This means, however, that their child cannot participate in these conversations and that the curriculum will not deal with their child's experiences. In this way, some parents back up the criticism of Tobin (1995) that the pedagogy of self-expression may privilege the already privileged.

Obviously, this study has shortcomings, such as the small sample, without any ambition whatsoever to be representative; the fact that several interviews were conducted with a translator, often an acquaintance of the parent, and it was not always clear if the translation was accurate; and as we said above, some of the interviews could not be tape-recorded. Nevertheless, the narratives of the parents may point to some important aspects of the discussion on the relationship between ECE and CSE. They suggest that the concept of school readiness and the subsequent narrow educational focus, albeit a policy inspired by a concern for social justice, may end up excluding precisely those it wishes to include.

The stories of the parents can also be interpreted as a strong argument for a relationship of strong partnership between ECE and CSE, such as the OECD's Starting Strong reports advocated. Indeed, what these parents are asking for is the integration of care within education, cherishing a holistic view of the child, with particular attention to emotional and social aspects (peer relationships) and careful transitions, in which the parents are involved. 
This may be precisely what child care (for children under 3 years in Flanders) has to offer to education, both kleuterschool and compulsory school.

The parents' narratives also suggest that parents should be involved not just in instrumental ways (e.g. to enhance school results) but are really listened to, even at the risk of challenging some of ECE's dearest assumptions (e.g. on experiential learning).

\section{Parents as researchers}

It is a recurring feature that what constitutes the problem that education is expected to solve (or who is considered to have a problem or to be a problem) is debated without the people concerned, reducing parents to spectators of the debate about themselves. The objective aura of science, moreover, yields the belief that educational problems are technical in nature, rather than political, and therefore can be addressed in technical ways that do not call for public debates. What is dangerous in this case is - as Dahlberg and Moss (2007) claim - not so much the presence of one dominant paradigm, but the absence of paradigmatic discussions.

What would happen if these critical remarks were to be taken seriously and questions about what needs to be studied and how were to be debated with those concerned? This is the challenge that has been taken up in France after the turmoil caused by INSERM's research on the prevention of adolescent delinquency (Institut National de la Santé et de la Recherche Médicale, 2005), published just after the riots in French suburbs in Autumn 2005, and its subsequent political use (Bénisti, 2005). In their report, INSERM suggested that the riots should be considered as delinquency, rather than as a protest against inequalities, and that the origins of this delinquency were located in early childhood, and more specifically in the deficiency of parents, especially parents from ethnic minorities. The report and its political translation formed the basis of a protest movement - Pas de zero de conduite pour les 0 à 3 ans (No zero for behaviour for the 0 to 3 years) - that rapidly gained over 200,000 supporters from among parents, social workers, pre-school teachers and others.

In this large protest movement against how parents were depicted in research about the prevention of juvenile delinquency (Le Collectif, 2006), groups of parents and practitioners refused to leave the construction of educational problems to scientists and claimed the right to do research on parenting themselves. The French NGO Association Collectif Enfants Parents Professionels started a project called Universités Populaires des Parents, in which existing and newly formed groups of parents conducted research, assisted by academics from various universities, with the explicit ambition to use the research to debate with policy 
makers about educational matters. After two years, the Flemish training organisation for the early years profession, Vormingscentrum Opvoeding en Kinderopvang, proposed to introduce the experiment in Flanders, in close collaboration with French colleagues ${ }^{3}$. Six groups of parents were formed to do research and debate their results with policy makers (for more on this project, see Roose, Roets and Vandenbroeck, forthcoming).

One of these groups, accompanied by two social workers and the first author, consisted of 14 parents, all attending the same basisschool (a combined kleuterschool and primary school) in a rather deprived area of Ghent: two Belgian mothers and a Belgian father, two mothers of Tunisian origin, one of Central African origin and eight mothers of Turkish origin. The starting point of this group was a complaint from the school that the parents were not 'involved' enough and a request from the deputy mayor for education to study the relationships between parents and school staff. The group met monthly for more than a year. Little by little the theme of the discussions changed. It started with a question about how to improve communication between teaching staff and parents. But gradually new themes emerged: 'How did we end up in this school?', 'How does one choose a school?', 'Can we please choose another school for our children?' The following scene occurred in one of the last meetings of the first year and represented a dramatic shift of focus:

A mother of Tunisian descent explains that she will not continue to come to the meetings after the summer holidays, as her daughter will then leave the school. She will go to a school whose name the mother is rather vague about. She tries different names, hoping that one of the other parents can recognize the sound. She tries "Oasis". "Is it De Oase?" asks the Belgian mother. "Yes", she nods, that was the name. "But", replies the Belgian mother, "that is a school for idiots!" Then she explains that it is a type of special education for children with intellectual disabilities. The Tunisian mother reacts: "That, I did not know." "Then why do you go there?" asks a second Belgian mother. "They told me I have to", says the Tunisian mother. I ask her if they told her why she has to. The mother looks down, stirs her coffee and shyly shakes her head, indicating that she has no idea why her daughter would need special education.

Then, the African mother explains that her daughter went to the bridging class, two years ago [a class after ECE, for children of 6 years, who are deemed to be not

\footnotetext{
${ }^{3}$ We gratefully acknowledge the cooperation with Meryem Usta and Rosheen Demaret (city of Ghent). We also thank Katelijne De Brabandere (VCOK) for guiding the project, the Flemish Youth Agency for support, and especially Rudi Roose and Griet Roets from the Department of Social Welfare Studies for inspiring discussions about the meaning of this project.
} 
school ready yet]. She was very pleased then about this initiative, since she agreed that her daughter was not ready for CSE. Now her son is in the last year of kleuterschool and they told her that he would have to go to the bridging class too. She told the staff that she disagreed with that, since he had already learned to read and write from his sister. I ask her what she thinks will happen in September at the start of the new school year. She says she does not know. Then I ask her why she thinks that her son was advised to attend the bridging class. The mother looks up, laughs aloud and says "Because we are Africans, of course!"

Then a Belgian mother tells her story about how her son was thrown out of class because his school bag contained a porn magazine. The next day she wanted to explain to the teacher that her son is bullied and this must have come from one of his classmates, as they never have porn magazines in their house. But the teacher refused to talk, commenting that it is always the same "with those stepchildren".

What happens in this meeting is that each parent tells a very personal story, but also that these stories are made collective and in so doing, the parents remark that it is not just about adding up personal stories. They see a common theme in their stories: the idea that the school has given up on their child, and on them as parents. One of the Turkish mothers gives a perfect résumé, saying, "In other schools they ask you a lot of questions. Here, nobody ever asks us anything". By the end of the meeting, the parents decide that they do not wish to work on improving the relationship with the staff anymore: their subject of concern is school choice. They wish to research why parents have "chosen" this school, how they can find another school for their children; and what kind of information you need as a parent to make informed choices.

The project thus started with a problem about parents, who were supposed not to be involved. Then it evolved towards a shared problem of communication between parents and staff. Finally it evolved again into a problem of parents, how to choose a better school; but also into a problem of school policy, how does one inform parents about their possibilities, which was discussed with the policy makers of the city. The difficult relationship of mistrust between staff and parents was not resolved, but the Deputy Mayor wrote a letter of appreciation to the parents and discussed with his team how in the future school staff could be counselled about their relationship with parents from diverse backgrounds. 
For the academics involved, the project started with the intriguing question: "What would happen if it is not researchers but parents that define what needs to be researched?" What we found out in this group (just as in most of the other groups) is that the answer to this question is highly unpredictable. Participative action research does not follow pre-ordained steps - formulate hypotheses, gather evidence, reflect on the hypotheses. Rather it is rhizomatic, always in the middle, always becoming, and never finished.

\section{Discussion}

The dominant conception of ECE as readying children for CSE is embedded in a preventive paradigm that goes well with neo-liberal individual meritocracy. In this ideal meritocratic society, everyone ends up with the position he or she deserves based on personal effort and choices. Education in this vein is a preparation for an economically prosperous life and ECE is necessary for a head start in this educational rat race, especially when the child is 'at risk'. Being at risk means being from poor families and/or families from ethnic minorities, since 'objective' research has shown that these children fail more often at school - and thus are at risk of later dependency on the State, juvenile delinquency, drug abuse and the like and thus objects of expensive interventions. In this sense, education contributes to the myth of personal achievement and of schooling as one of the most salient pathways to upward social mobility. Sociologists (e.g. Bourdieu and Passeron, 1970), however, have long since shown that educational systems tend to reproduce and perpetuate the existing social stratification, rather than change it.

Yet, as a result of the dominant construction of what education is about, the problem of school failure of children from poor and ethnic minority families is not considered as a problem of the school or of the educational system anymore. It is now considered as a problem of individual children and their families. Poor parents are, historically and at present, almost automatically associated with poor parenting (George, 2010). This deep, historically rooted mistrust of parents has lead to interventions in the family, shaped as parent support programmes, leading to the pedagogicalization of parents (Popkewitz, 2003) and especially to their instrumentalization. By this we mean that parents are expected to be involved insofar as this is 'helpful' for achieving the outcomes the school has set for the child, but not involved in discussion about these very outcomes.

The mistrust of parents also leads to the growing importance of the readying function of ECE, particularly for those children 'at risk', since the State is expected to take over where the parents fail. In the meantime, CSE can carry on with 'business as usual', meaning the 
education of the alleged average child. Indeed, the very concept of 'school readiness' becomes some kind of a standard or norm, a measure against which children are categorized, in the meaning Foucault (1975) gave to this concept:

La pénalité perpétuelle qui traverse tous les points, et contrôle tous les instants des institutions disciplinaires compare, différencie, hiérarchise, homogénéise, exclut. En un mot elle normalise ${ }^{4}$.

The excluding mechanisms of the readying relationship between ECE and CSE affect not only ECE, but also CSE. Since the function of ECE is to make children 'school ready', CSE can start with the average child, the one that fits in the system. We can witness how CSE today is less well equipped to deal with diversity (see for instance the growing number of ethnic minority children who are referred to special education, the rising numbers of diagnoses of early autism, ADHD and other alleged dysfunctions). The average child, the one that fits, is presented as natural and 'normal', going well with the myth of meritocracy telling us that each one of us eventually gets what he or she deserves. As Freire (1970, $p$. 144) said:

The people are manipulated by...yet another myth: the model of itself, which the bourgeoisie presents to the people as the possibility for their own ascent. In order for these myths to function, however, the people must accept the word of the bourgeoisie.

School readiness is a myth and a construct that is believed to be an individual quality of the child, influenced by her family background. In his introductory essay, Peter Moss explained how this affects ECE. We have to elaborate on this, showing how it also affects CSE as well as how it excludes particular groups of parents. We have attempted to counterbalance this by giving voice to some of these parents.

Listening to these parents, we suggest a possible alternative to the concept of school readiness: child (and family) readiness of the school. The 'child' in 'child ready' is not an average child. It is a unique child, a child that we do not know before we have met her and her family. A child that will have similarities and differences with the children we have met so far. A child with a family that will resemble and differ from families we know. A child,

\footnotetext{
${ }^{4}$ The perpetual coercion that penetrates every point and controls all the moments of the disciplinary institutions compares, differentiates, hierarchizes, homogenizes, excludes. In one word: it normalizes (Foucault, 1975, p.185; original emphasis; translation by the authors).
} 
therefore, that is fundamentally unpredictable. Being ready for that child, therefore, means being ready for unpredictability and uncertainty and, consequently, being ready to search and to research what ECE may mean for this child and for his family.

This is not to say that ECE cannot have a function of readying children. For some families, this is precisely what they expect. Some immigrant families, for instance, do not choose child care as a 'home away from home', but precisely because it differs from the home: it is a place for learning the dominant language and for socializing their children, holding out the prospect of integration and social capital (Vandenbroeck et al., 2009). But it is to say that whether ECE has this function or not, and especially how this function is shaped in practice, is the result of on-going negotiations between local communities, practitioners, management, policy makers - and parents.

In order to make these negotiations reciprocal, a series of conditions need to be fulfilled: reflective practitioners supported by a reflective system that gives them resources and time to document and discuss their practices; above all, a vision of education as a public good and as a transitional space between the private and the public spheres. As Arianna Lazarri (2011b) has shown in her well documented PhD study of early childhood teachers in Bologna, it is no coincidence that the inspiring pedagogues from northern Italy, such as Loris Malaguzzi and Bruno Ciari, reacted against the experience of fascism with a deep commitment to democratic aspects of education, education of, by and for the people. In her historical analysis of present-day professionalism in Bologna, Lazarri shows how this is embedded in civic traditions of solidarity and participation by citizens in the political life of their communities and in the development since the late 1960s in municipal ECE of gestione sociale or social management. Italian authors throughout the 1970 s and 1980s describe early childhood institutions as 'laboratorio cultural', cultural laboratories in which 'all actors policy makers, practitioners, families and citizens - were involved in the construction of a common project for social and cultural transformation' (Balduzzi in Lazarri, 2011) (for a fuller discussion, see Chapter Seven).

Listening to parents, we learn that we cannot construct an image of the child without an image of the parent. It is not possible to respect the child without respecting the parent. The reciprocal negotiation with parents, however, is a risky adventure, as we expose some of our dearest assumptions to questioning. But so is democracy itself a risky adventure.

The Flemish experience, as we have analysed it, can be considered as a plea to at least take into account alternative meanings of the relationship between ECE and CSE. There is a case 
for a strong and equal partnership and for a meeting place. This is what actually happens in some municipal kleuterscholen in the city of Ghent, which acknowledge that the experience of child care services for the youngest children has much to offer to education. Kleuterschool teachers sit together with child care professionals, and ask the latter to support them in working with parents from diverse origins, in order to discover new ways of experiential learning, in which the experiences of all children are taken into account. Notwithstanding the fundamental inequality in the relationship between child care and education (i.e. child care practitioners have lower qualifications, lower salaries, more working hours and less holidays), these tentative meetings between the two professional groups offer some hope that the meeting place Peter Moss explained in his introductory essay may be possible, and remind us of the words of Freire (1970, p. 92)

Men are able to transcend the limit-situations to discover that beyond these situations - and in contradiction to them - lies an untested feasibility. 